\title{
Current Short Circuit Implementation for Performance Improvement and Lifetime Extension of Proton Exchange Membrane Fuel Cell
}

\author{
Yuedong Zhan ${ }^{\mathrm{a},}$, Youguang Guo ${ }^{\mathrm{b}}$, Jianguo $\mathrm{Zhu}^{\mathrm{b}}$ and $\mathrm{Li} \mathrm{Li}^{\mathrm{a}}$ \\ ${ }^{\mathrm{a}}$ Department of Automation, Kunming University of Science and Technology \\ Kunming, 650500, China
}

${ }^{\mathrm{b}}$ Faculty of Engineering and Information Technology, University of Technology, Sydney

PO Box 123, Broadway, NSW 2007, Australia

(Emails: Ydzhan@163.com, Youguang.Guo-1@uts.edu.au,Jianguo.Zhu@uts.edu.au) *Corresponding author: Tel.: +86 871 5623806; Fax: +86 871 5916643, Email address: Ydzhan@163.com (Yuedong Zhan)

\begin{abstract}
To improve its performance, extend its lifetime, and overcome the problem of the slow dynamic during the start-up and the operation process of PEMFC, this paper presents current short circuit and smart energy management approaches for a main PEMFC with auxiliary PEMFC, battery and supercapacitor as hybrid power source in parallel with an intelligent uninterrupted power supply (UPS) system. The hybrid UPS system consists of two low-cost 63-cell 300W PEMFC stacks, 3-cell lead-acid battery, and 20-cell series-connected supercapacitors. Based on the designed intelligent hybrid UPS system, experimental tests and theoretical studies are conducted. Firstly, the modelling of PEMFC is obtained and evaluated. Then the performance improvement mechanism of the current short circuit is proposed and analysed based on the Faradaic process and
\end{abstract}


non-faradaic process of electrochemical theory. Finally, the performances of the main PEMFC with the auxiliary PEMFC/battery/supercapacitor hybrid power source and intelligent energy management are experimentally measured and analysed. The proposed current short circuit method can significantly extend the lifetime, improve the performance of PEMFC and decrease the size of the main FC for stationary, backup power sources and vehicular applications.

Keywords: Proton exchange membrane fuel cell; Voltage Modelling; Current short circuit; Faradaic process and nonfaradaic process; Uninterrupted power supply system

\section{Introduction}

Hydrogen and fuel cells (FCs) are the third-fastest growing renewable energy industry after wind and solar energies, realizing tremendous benefits for the environment, economic energy competitiveness and specific FC applications, such as power generation system, distributed energy, specialty vehicles, light-duty vehicles, transit buses, backup power, auxiliary power, portable power, and motive power. These benefits include highly efficient energy conversion, reducing air pollution, reducing oil consumption, fuel flexibility including renewable and clean fuels, quiet operation, low maintenance demand, grid support capability, and opportunity for economic growth and leadership in emerging high-tech sectors [1].

Proton exchange membrane fuel cell (PEMFC) and direct methanol fuel cell (DMFC) are emerging as an economically viable selection for providing uninterrupted power supply (UPS) systems, which play a very important role in the backup and emergency power supply applications, particularly for computers, medical/life support systems, communication systems, office equipment, industrial controls, hospital instruments, and integrated data center to supply uninterrupted and reliable constant voltage and constant 
frequency power in case of power failure [2]. For instance, US Department of Energy (DOE) funded 18 FC backup power systems at 10 installation sites will help accelerate the deployment of clean technology at Federal government facilities and provide valuable data and feedback for FCs [3].

However, the primary technology challenges facing the development of PEMFC for the applications as mentioned above are the durability, cost and performance of the FC. The cost and durability present two of the most significant challenges to achieving reliable, clean, cost-effective FC systems. While addressing cost and durability, FC performance must meet or exceed that of competing technologies [4, 5]. A PEMFC generating system, using a perfluorinated sulfonic acid (PFSA) membrane and with self-humidified, air-cooling and air-breathing PEMFC stack, will encounter the problems like voltage drop. It is difficult to achieve the best performance every time after the FC starts up and during operation process. At the cathode side, as oxygen from the air is supplied by diffusion and natural convection, the poor transportation of air, heat and water managements are the crucial issues. At the anode side, hydrogen fed is usually in dead-end mode and may even cause hydrogen starvation because of flooding and other causes. In order to overcome these limitations, many researches for air-breathing PEMFCs have been recently carried out from their internal structure design and employing the newest materials [6-9].

On the other hand, the UPS system with backup PEMFC/battery/supercapacitor hybrid power sources should ensure that there is enough fuel and battery/supercapacitor capacity to provide the power needed by the external load. When the utility grid power source is interrupted, the hydrogen will be supplied to PEMFC stack. However, during the 10 s start-up time of the stack, or a sudden change of external load, the hydrogen cannot be fed fast enough, and the FC stack may take a few seconds to reach the required output voltage. To overcome this issue, another PEMFC is used in parallel, 
composed of a redundant system. Meanwhile, the rechargeable battery or supercapacitor can be used to respond fast to the external load, protecting the PEMFC from fuel starvation and degradation.

Studies on the current short circuit methods to improve the performance and extend the lifetime of the PEMFC have not been reported. However, many scholars have done a lot of research on the starvation prevention and lifetime extension of the FCs in other cases. Recently, a review article [10] indicated the main factors affecting the lifetime of PEMFC in vehicle applications, such as the water management problems, reactant starvation issues, and the effects of the operating parameters on the PEMFC dynamic response.

According to the theory analysis and experimental investigation, appropriate current short circuit can improve the performance and extend the lifetime of the FCs. At the moment of using the current short circuit, because of a large current, the extra water produced in the gas diffusion layer (GDL) can be evaporated rapidly. And the surface on the membrane electrode assembly (MEA) will produce the right amount of moisture evaporated rapidly as mentioned above, which is conducive to enhancing the activity of membrane electrode active particles. Simultaneously, the double-layer capacitance voltage can be discharged rapidly, which makes the potential drop across the diffuse layer in the catalyst layers (CLs) of MEA become the smallest, so the potential degradation is the slowest.

Based on the ideas above, this paper, in order to enhance the activity of MEA, prevent PEMFC from flooding and starvation in the GDL, improve its performance, lengthen its lifetime, and overcome the problem of the slow dynamic during the start-up and the operation process of air-breathing PEMFC, presents a current short circuit and smart energy management strategy in a main PEMFC generating system with an auxiliary 
PEMFC/battery/supercapacitor hybrid power source developed for UPS applications. Fig. 1 shows the schematic diagram of the UPS system, including two $300 \mathrm{~W}$ PEMFC stacks, 3-cell lead-acid batteries in series, 20-cell supercapacitors in series, a single phase high frequency UPS, and the intelligent control unit. In Fig. 1, the auxiliary FC, supercapacitor and battery are connected to the DC bus directly. According to the load and the measurement values of current $\left(\mathrm{I}_{1}-\mathrm{I}_{4}\right)$ and voltage $\left(\mathrm{V}_{1}-\mathrm{V}_{4}\right)$ for the main and auxiliary PEMFCs, batteries and supercapacitors, the intelligent control unit can control the turning on and off of current short circuit switches SC1 and SC2, and the power switches K1-K4, and determine the required power sources for UPS. The "current short circuit" means shorting the two output terminals FC+ and FC- of the two PEMFC stacks' end plates, as shown in Fig. 1.

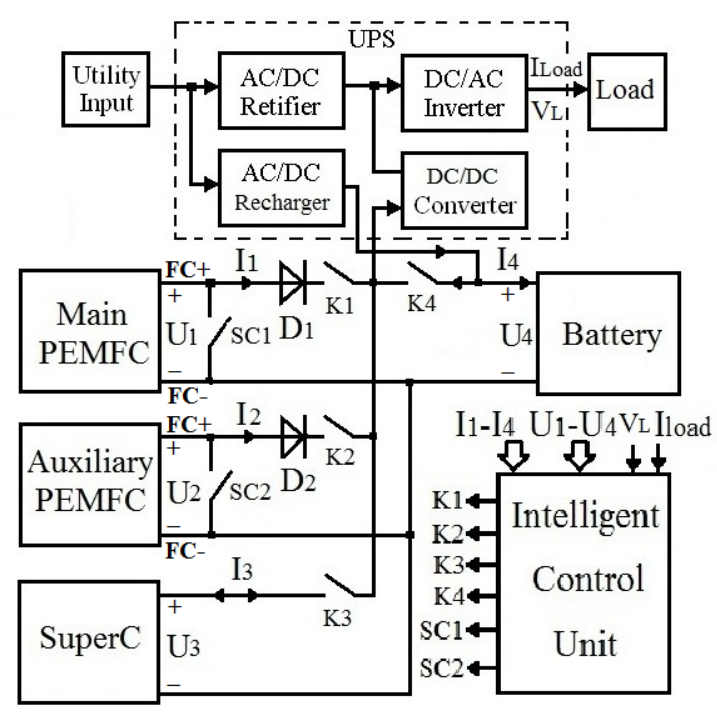

Fig. 1. Block diagram of UPS system with backup PEMFC, battery and supercapacitor hybrid power sources

Because of the voltage drop and slow dynamic performance of PEMFC stack during starting up and the operation process, another PEMFC, a small capacity battery and supercapacitors in series are employed in parallel to improve the performance of the main PEMFC generating system, and supply power sources for the UPS system, when the utility grid is interrupted and/or during the responding time to sudden change of the load. 


\section{Voltage modeling of PEMFC}

The PEMFC is a type of the electrochemical energy conversion device, and the output voltage can be obtained as [11]

$$
\begin{aligned}
V_{\text {stack }} & =E_{\text {reversible }}-V_{\text {actLoss }}-V_{\text {OhmicLOSS }}-V_{\text {concLOSs }}-V_{\text {leakLOSS }} \\
& =E_{\text {reversible }}-N\left\{\frac{R T}{\alpha n F} \ln \left(\frac{i+i_{n}}{i_{0}}\right)+R_{\text {Ohmic }}\left(i+i_{n}\right)+\frac{R T}{n F}\left(1+\frac{1}{\alpha}\right) \ln \left[\frac{i_{L}}{i_{L}-\left(i+i_{n}\right)}\right]\right\}
\end{aligned}
$$

where $V_{\text {actLOss }}$ is the activation voltage loss (V); $V_{\text {OhmicLOss }}$ Ohmic voltage loss (V); $V_{\text {concLOSS }}$ concentration voltage loss $(\mathrm{V})$; $V_{\text {leakLOSS }}$ leakage loss voltage (due to internal current) (V); $E_{\text {reversible }}$ the reversible voltage (V); $N$ the number of cells in a PEMFC stack; $\alpha$ the transfer coefficient; $n$ the number of electrons per molecule of $\mathrm{H}_{2}$ (2 electrons per molecule); $R$ the universal gas constant $\left(\mathrm{J} \cdot \mathrm{mol}^{-1} \cdot \mathrm{K}^{-1}\right) ; T$ the stack temperature $(\mathrm{K}) ; \quad F$ the Faraday's constant $\left(\mathrm{C} \cdot \mathrm{mol}^{-1}\right) ; R_{\text {Ohmic }}$ the area-normalized resistance, also known as area specific resistance (ARS) of the PEMFC measured $\left(\Omega \cdot \mathrm{cm}^{2}\right) ; i_{0}$ the exchange current density $\left(\mathrm{A} \cdot \mathrm{cm}^{-2}\right) ; i_{L}$ the limiting current density at which the cell voltage will fall rapidly $\left(\mathrm{A} \cdot \mathrm{cm}^{-2}\right) ; i_{n}$ the internal current density or parasitic current that is wasted $\left(\mathrm{A} \cdot \mathrm{cm}^{-2}\right)$; and $i$ the PEMFC stack current density $\left(\mathrm{A} \cdot \mathrm{cm}^{-2}\right)$.

The reversible voltage at varying temperatures and pressures can be expressed as

$$
E_{\text {reversible }}=N\left\{E^{0}+\frac{R T}{2 F} \ln \left[\frac{P_{\mathrm{H}_{2}}\left(P_{\mathrm{O}_{2}}\right)^{\frac{1}{2}}}{P_{\mathrm{H}_{2} \mathrm{O}}}\right]+\frac{\Delta \bar{S}_{298.15 K}}{n F}(T-298.15)\right\}
$$

where $P_{i}$ is the partial pressure of species $i$ ( $i$ is $\mathrm{H}_{2}, \mathrm{O}_{2}$ /air, or liquid water at cathode side) $(\mathrm{kPa})$, respectively; $E^{0}$ the cell open circuit voltage $(\mathrm{OCV})$ at the Standard 
Temperature and Pressure (STP) (V); and $\Delta \bar{S}_{298.15 K}$ change in the molar entropy at STP $\left(\mathrm{J} \cdot \mathrm{mol}^{-1} \cdot \mathrm{K}^{-1}\right)$.

According to the voltage output equation above, an equivalent circuit for electrochemical circuit model of PEMFC is obtained, as in Fig. 2, where $C$ is the equivalent capacitor due to the double-layer charging effect (F); $V_{c}$ is the voltage across the capacitor $(\mathrm{V}) ; \quad R_{\text {act }}$ is the activation resistance $(\Omega)$; and $R_{\text {conc }}$ is the concentration resistance $(\Omega)[12]$.

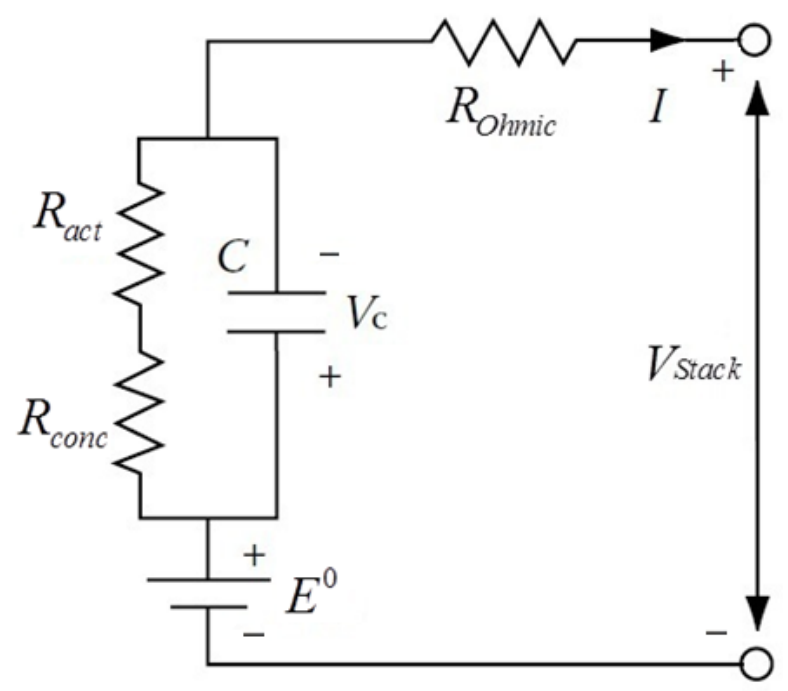

Fig. 2. Equivalent circuit of a PEMFC

\section{Performance improvement mechanisms of current short circuit}

So far, a variety of catalysts in a PEMFC have been investigated. However, Pt-containing catalysts are still the most popular and important components within a MEA due to the low overpotential and high catalytic activity of Pt for the hydrogen oxidation reaction and the oxygen reduction reaction, as all the electrochemical reactions are realized with the aid of the catalyst and take place on its surface. As the heart of a PEMFC, the MEA is generally composed of a PEM sandwiched between two electrodes with the CLs on either side. Normally, a CL spreads on a GDL. The 
catalyst-coated membrane (CCM) is a form of MEA developed to improve the performance of PEMFCs, with CLs on both sides of the membrane. A carbon-supported Pt (or Pt-alloy) catalyst, together with a recast Nafion ${ }^{\circledR}$ ionomer network, forms a complex composite CL with multiple interfaces, which is critical for the transport of reactant gas, hydrated $\mathrm{H}^{+}$proton, electrons, and water. Both the structure and the composition of the CL have been found to be important in improving cell performance.

According to the electrochemical theory, there are two types of processes occurring at the electrodes. One is the Faradaic process, and the other is non-faradaic process [13].

\subsection{Faradaic process and factors affecting rates of electrodes reactions}

From Faraday’s law, since electrode reactions are heterogeneous, their reaction rates are usually described as

$$
\operatorname{Rate}\left(\mathrm{mol} \cdot \mathrm{s}^{-1} \cdot \mathrm{cm}^{-2}\right)=\frac{d N}{d t}=\frac{i}{n F}
$$

where $N$ is the mol electrolyzed (mol).

In general, the electrode reaction rate (or current) is controlled by the rates of processes, such as the mass transfer, electron transfer at the electrode surfaces, chemical reactions preceding or following the electron transfer, and the other surface reactions of adsorption and desorption.

At the moment when the current short circuit is applied in the PEMFC control system, because the load resistance is almost zero, the current in the PEMFC stack is the maximum, so the electrode action rate tends to be the maximum. When the current short circuit is applied, because of a large current, the extra water produced in the GDLs of the MEA can be evaporated rapidly. Therefore, the reactant gas can transfer to CLs quickly, and the performance of PEMFCs can be improved. 
On the other hand, the moisture evaporated rapidly can enhance the activity of membrane electrode active particles in the surface of MEAs. Therefore, their maximum reaction rates can accelerate the rate-determining steps creating their productions or disposing of their reactants.

\subsection{Nonfaradaic process and behavior of electrode-membrane interface}

The processes such as the adsorption and desorption can take place, and the structure of the electrode-membrane interface can change with changing potential or membrane composition, which is called nonfaradaic processes.

The nonfaradaic processes are the nature behavior of the electrode-membrane interface. According to the electrochemical theory, because the charge cannot cross the ideal polarized electrode (IPE) when the potential across it is changed, the behavior of electrode-membrane interface is similar to that of a capacitor C, as shown in Fig. 2.

The whole array of charged species and oriented dipoles existing at the metal-solution interface is called the charge double layer (CDL). At a given potential, the electrode-membrane interface is characterized by the double-layer capacitance C. Unlike a real capacitor, whose capacitance is independent of the voltage across it, $\mathrm{C}$ is the function of potential, which is

$$
\begin{gathered}
V_{\text {Stack }}=N\left(E^{0}-R_{\text {Ohmic }} I-V_{C}\right) \\
V_{C}=\frac{\Delta Q}{C} \\
\Delta Q=I T_{\text {disc }}
\end{gathered}
$$


where $V_{C}$ is the double-layer capacitance voltage $(\mathrm{V}) ; \Delta Q$ the changing amount of the electrical charge (C); I the PEMFC stack current (A); and $T_{\text {disc }}$ the discharging time (s).

According to the double-layer structure models, the specific adsorption of ions can affect the electrode reaction kinetics, which is sometime called the Frumkin effect [13]. In a double-layer structure model, there are an inner layer and a diffuse layer. The inner layer is also called the compact, Helmholtz, or Stern layer. The locations of the electrical centers of the specifically adsorbed ions are called the inner Helmholtz plane (IHP), and the locus of centers for these nearest solvated ions is the outer Helmholtz plane (OHP).

Based on the Gouy-Chapman model and theory, the potential distribution in the diffuse layer can be expressed as [13]

$$
\begin{gathered}
\frac{\tanh (z e \phi / 4 \sigma T)}{\tanh \left(z e \phi_{0} / 4 \sigma T\right)}=e^{-\kappa x} \\
\kappa=\left(\frac{2 n^{0} z^{2} e^{2}}{\varepsilon \varepsilon_{0} \sigma T}\right)^{1 / 2}
\end{gathered}
$$

where $z$ is the magnitude of the charge on the ions; $e$ the charge on the electron; $\sigma$ the Boltzmann constant $\left(\mathrm{J} \cdot \mathrm{K}^{-1}\right) ; T$ the absolute temperature $(\mathrm{K}) ; \varepsilon$ the permittivity; $\varepsilon_{0}$ the vacuum permittivity; $n^{0}$ the number of concentration of each ion in the bulk $\left(\mathrm{cm}^{-3}\right) ; \kappa$ the double-layer thickness parameter $\left(\mathrm{cm}^{-1}\right) ; \phi$ the electrostatic potential (V); and $\phi_{0}$ the potential at $x=0$ relative to the bulk of MEA (V), which is the potential drop across the diffuse layer.

Equation (7) describes the potential profiles of the diffuse layer, and the potential always degrades from the interface of the MEA. Because the diffuse layer is relatively 
compact, at large $\phi_{0}$, the potential $\phi$ drops quickly. As $\phi_{0}$ becomes smaller, the potential decline is more gradual.

Therefore, in this PEMFC system, at the moment of using the current short circuit method, the double-layer capacitance voltage $V_{C}$ can be discharged rapidly, which makes the $\phi_{0}$ in the CLs of MEAs become the smallest, and the potential degradation is the slowest.

\section{Experimental setup and results}

\subsection{Experimental setup}

To validate the performances and lifetime of the two PEMFCs, real input and output data are measured on the main PEMFC, auxiliary PEMFC, batteries and supercapacitors. The experimental setup consists of a UPS system, the PEMFC generating and test system, 3-cell deep cycle lead-acid batteries, 20-cell supercapacitors in series and a data-acquisition system, which includes multifunction I/O devices NI6036E, analog voltage output devices NI6713, parallel digital I/O interface PCI-6503 and analog multiplexer with temperature sensor AMUX-64T. The current signals were measured by LEM LA100-P current transducers, the output voltage signals were measured by LEM LV25-P voltage transducers, and the temperature was measured by a k-type thermocouple together with an analogue connector.

The UPS system with backup main and auxiliary PEMFCs, supercapacitor and battery provides the AC power source and controls the linear loads (e.g. lamp box) and nonlinear loads (e.g. PC), while the data-acquisition system measures and records the required information. In the PEMFC generating and test system, both hydrogen and air are regulated by mass flow controllers (type: F-201C-GAS-22V and 
F-112AC-GAS-22V, Bronkhorst). Concerning the application of the PEMFC power system in UPS system, the option to humidify the hydrogen is not used. The temperature and humidity of air and hydrogen can be measured at inlet by the hydrotransmitter (type: HD2008TV1, Delta OHM) as well as the pressure transmitter (type: AUS EX 1354X, Burkert) between the inlets of cathode and anode. The output of the UPS is connected to a lamp load that is used in a constant voltage mode. All physical parameters such as currents and voltages of UPS, PEMFC stack, supercapacitor and battery, gas mass flow of the reactants, pressure drop in the flow fields, relative humidity and temperatures of air and hydrogen are recorded with the data-acquisition system.

Fig. 3 indicates the PEMFC data-acquisition and monitoring control system with component details, which consists of two stacks, water-cooling components, air-cooling, $\mathrm{H}_{2}$ humidifying and filtering, and feed mass flow rates, temperature and pressure control and monitoring. Three types of gases, hydrogen, nitrogen and air/oxygen, are used in the system. A LabVIEW ${ }^{\mathrm{TM}}$ software package designed by ourselves is used to control the whole process. In Fig. 3, the SCU indicates the current short circuit control unit. Fig. 4 shows the test bench of hybrid PEMFCs, battery, and supercapacitor system. 


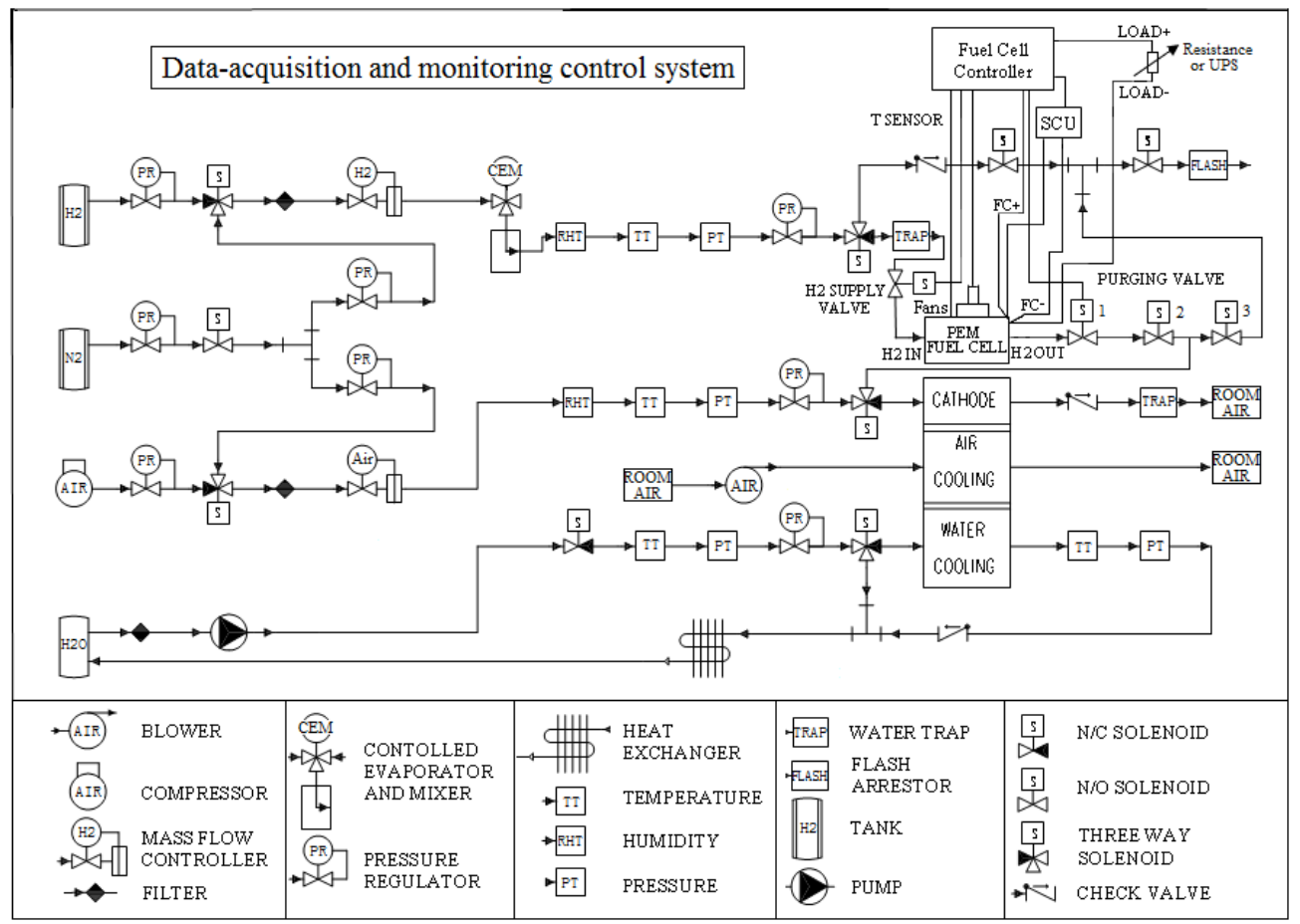

Fig. 3. Schematic diagram of the PEMFC generating and test control system

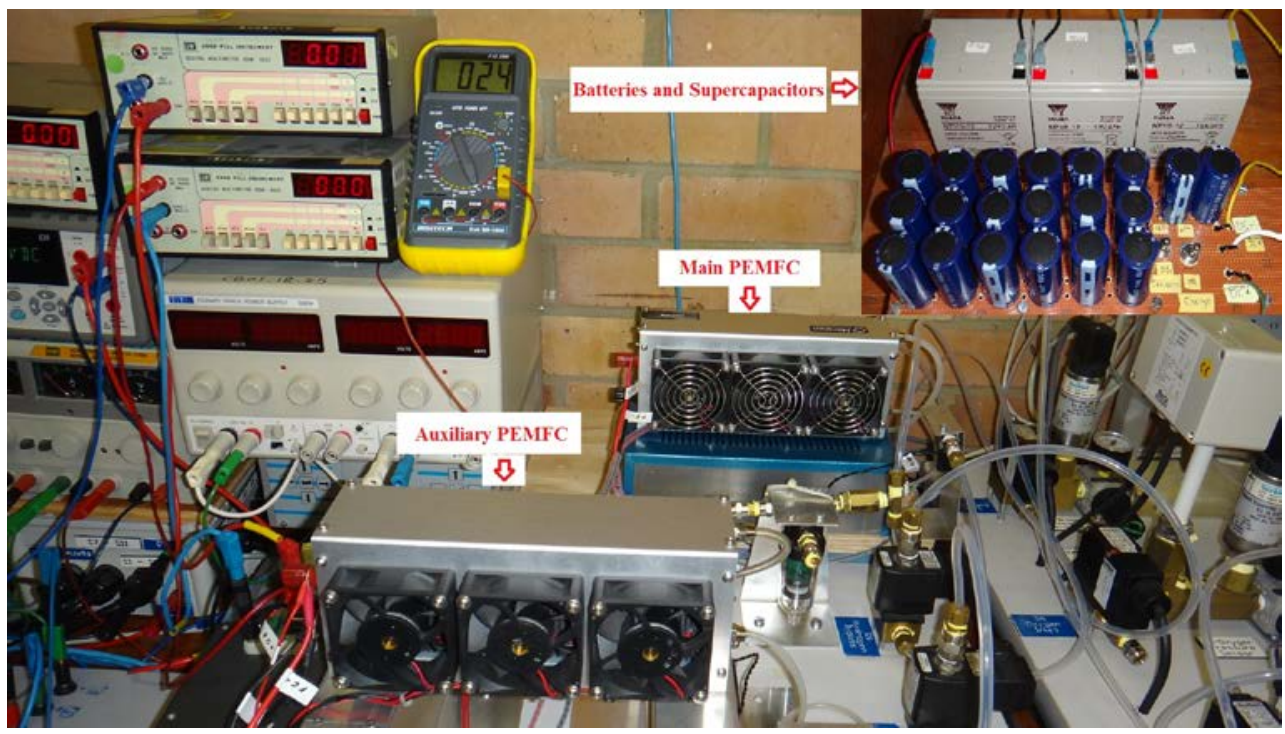

Fig. 4. Hybrid PEMFCs/battery/supercapacitor system test bench

The lifetime extension and performance improvement testing under various operating conditions were carried out on the two 300W PEMFC generating and test system by our own design and manufacturing. During the testing, the two 63-cell PEMFC stacks were operated at different currents of 0-10 A. The temperature of two stacks was kept at $24-55{ }^{\circ} \mathrm{C}$ and the pressure of hydrogen was controlled at 50-55kPa. The flow rates for 
hydrogen were set at 3.9 and 1.2 standard litres per minute (SLPM) or at 1.2-1.5 stoichiometry of hydrogen.

\subsection{Experimental results and discusion}

According to the electrochemical circuit model and voltage equation of PEMFC, a value of about $1.23 \mathrm{~V}$ for a cell operating below $100{ }^{\circ} \mathrm{C}$ is calculated and used in theoretical analysis. However, when a PEMFC is made and put into use, it is found that the voltage is less than this value, often considerably less. Fig. 5 shows the performance of a new air-breathing, self-humidified and 63-cell stack operating at about $24-55{ }^{\circ} \mathrm{C}$, hydrogen at 50-55 $\mathrm{kPa}$ and normal air pressure after starting up and during the initial operating conditions with and without a current short circuit method. In Fig. 5, firstly, the stack OCV is less than the theoretical value of $58 \mathrm{~V}$, in which the voltage of each cell is about $0.921 \mathrm{~V}$. Secondly, there is a rapid initial fall in voltage. After operation for several minutes, the voltage goes up because the temperature in the stack has gone up, but it is still less than the normal value. In general, the activation voltage loss is the main reason of voltage drop when not under load, according to the voltage model of PEMFC. If a PEMFC stack runs under no load, it will cause the performance degradation of the stack. When the PEMFC stack runs under no load using the current short circuit mode, the performance degradation can be avoided, which can enhance the life by shortening the time the cells sit at full open circuit potential $(\sim 1 \mathrm{~V})$.

To date, some scholars have made a quantitative explanation for such behaviour that the open circuit potential is not equal to the reversible due to a combination of a finite electronic short and finite hydrogen cross-over leak across the membrane. These result in small equivalent currents in the cell that cause overpotential due to the oxygen reduction reaction kinetics. Gasteiger et al. [14] quantified the activities and voltage loss modes for the MEAs, specified performance goals needed for automotive application, and provided benchmark oxygen reduction activities for state-of-the-art platinum 
electrocatalysts by analysis of the voltage loss terms in the $\mathrm{H}_{2}$ /air MEAs. One explanation attributes this behaviour to activation losses, fuel crossover and/or internal current, Ohmic losses and mass transport or concentration losses as described in the FC book written by Larminie and Dicks [15]. The combined effects of internal short circuit, fuel crossover, and parasitic oxidation reactions occurring at the cathode side are the difference between the measured open circuit cell voltage and the theoretical cell potential [16].

Secondly, if it is unreasonable to design the flow field in the stack, because of flooding, the sluggishness of hydrogen to the anode side will occur. The cell performance of an air-breathing PEMFC is not as good as that of desired stack. And if there is no convective flow for the anode to help manage the water balance in the system, it will lead to starvation, which is a crucial issue to make the performance of the PEMFC degrade.

Finally, the charge double layer is important in understanding the dynamic electrical behaviour of MEA for the PEMFC. According to Larminie and Dicks [15], the charge double layer gives an explanation that the activation overvoltage occurs. As the possibility of the reaction taking place obviously relies on the density of the charges, electrons, and $\mathrm{H}^{+}$ions on the electrode and electrolyte surfaces of PEMFC. The more the charge is, the greater the current is. Moreover, any collection of charge, such as the electrons and $\mathrm{H}^{+}$ions at the electrode-membrane/electrolyte interface will generate an electrical voltage. That is, in this case, there is the activation overvoltage and it leads to the voltage drop.

A current short circuit (CSC) method can be designed to prevent the PEMFC from voltage drop and starvation, enhance the activity of catalyst in the MEA, and improve the performance of air-breathing PEMFC. According to Section 3, when the CSC is 
periodically used, the right amount of moisture produced in the MEA is conducive to enhancing the activity of membrane electrode active particles. The large amount of water produced in the GDLs will be evaporated and removed by purging rapidly. Thus, the fuel can reach the anode/cathode fast. On the other hand, the charge layer on or near the anode and cathode interface is a store of electrical charge and energy, and as such behaves much like an electrical capacitor. The CSC could dissipate the charge quickly, and makes the potential drop across the diffuse layer in the CLs of MEAs become the smallest, and the potential degradation becomes the slowest. Based on the experimental investigation, according to the current value, the interrupting cycle is set up from $10 \mathrm{~s}$ to $50 \mathrm{~s}$, and the interrupting time of CSC is set up in the range of $20 \mathrm{~ms}$ to $200 \mathrm{~ms}$. The more the current, the shorter the interrupting cycle and time of CSC. Therefore, the CSC could make the activation overvoltage immediately follow the current in the way that the Ohmic voltage drop does. The result is that even if the current suddenly changes, the operating voltage shows an immediate change due to the internal resistance, but moves fairly and quickly to its final equilibrium value, as shown in Fig. 5.

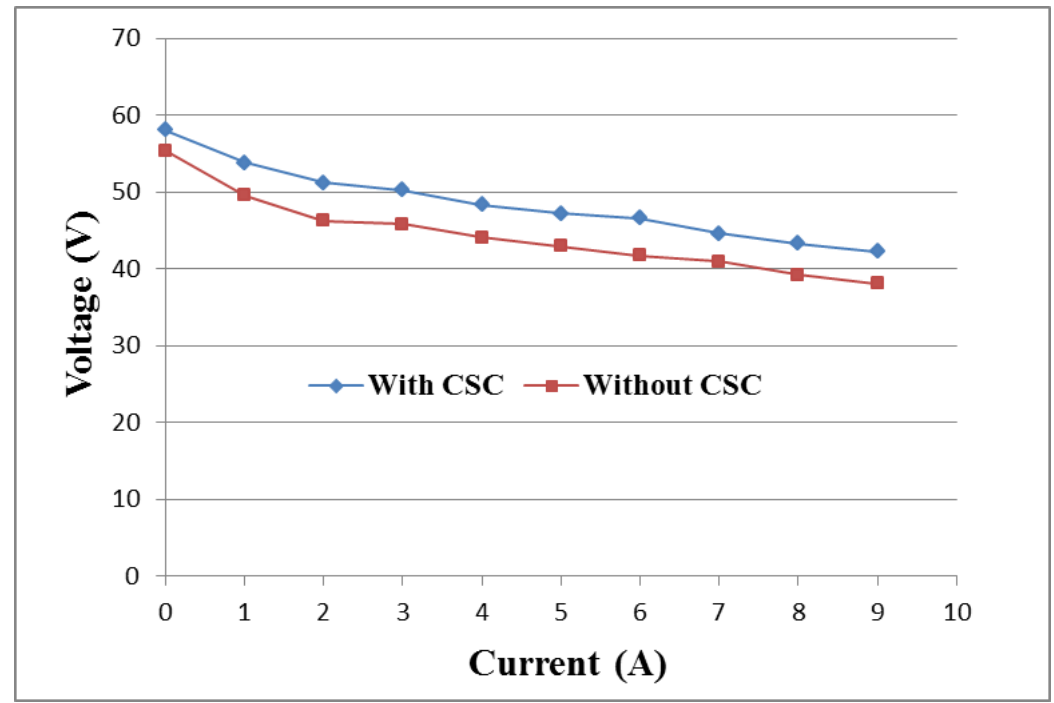

Fig. 5. Polarization curves of air-breathing stack with and without a current short circuit (CSC) control: temperature at $24-55^{\circ} \mathrm{C}$; pressure of hydrogen at $50-55 \mathrm{kPa}$; stoichiometry of hydrogen at 
When the current short circuit is put into practice, the following control strategy can be chosen. Using the CSC for 10 minutes and no CSC for the rest during one hour, the loss of PEMFC performance would be small. However, when the CSC has not been used in the PEMFC for a long time, the voltage decline can reach an attenuation of up to $20 \%$.

Fig. 6 shows the long-term performance of a new air-breathing stack with the CSC method, which does not deteriorate much after the 5500 hours of accumulative operation. One of two 300W PEMFC stacks was bought in March 2008, and the other was bought in September 2012, and both of them were used to conduct research until now. There were 3 to 5 times start/stop cycles experienced every day during the two years. At night, there was a continuous experimental operation for 12 hours when both stacks ran in parallel. In order to verify the validity of the current short circuit, we did the experimental research without using the CSC for a PEMFC for about $1000 \mathrm{~h}$ accumulatively. After $1000 \mathrm{~h}$, the degradation rate of the PEMFC was $2.4 \mathrm{mVh}^{-1}$, as shown in Fig. 6.

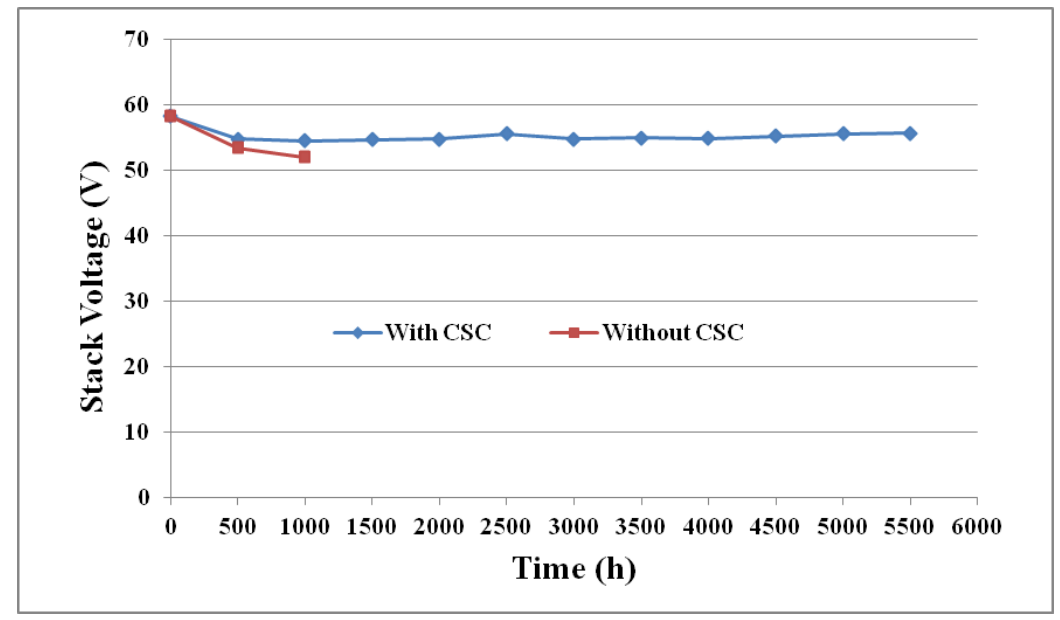

Fig. 6. Long-term performances of air-breathing stack with and without a current short circuit (CSC) method: temperature at $55^{\circ} \mathrm{C}$; pressure of hydrogen at $50-55 \mathrm{kPa}$; stoichiometry of hydrogen at 1.5; current at $4.3 \mathrm{~A}$

When the CSC method is employed in the PEMFC control process, there are two issues: one is that the CSC operation will result in loss of system efficiency, as shown in Fig. 7, 
where the PEMFC efficiency is less than 35 \%. Fig. 8 shows the UPS system efficiency with the load change. Relatively, the system efficiency using the CSC is less than that without using the CSC. In fact, without using the CSC, the performance of PEMFC will decline.

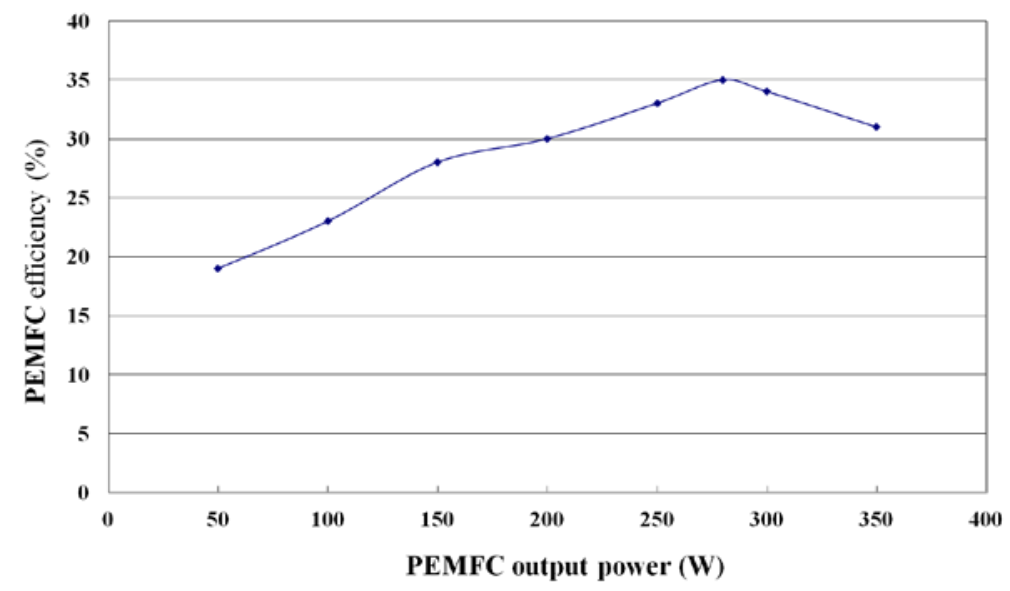

Fig. 7. PEMFC efficiency measured in the UPS system using the CSC

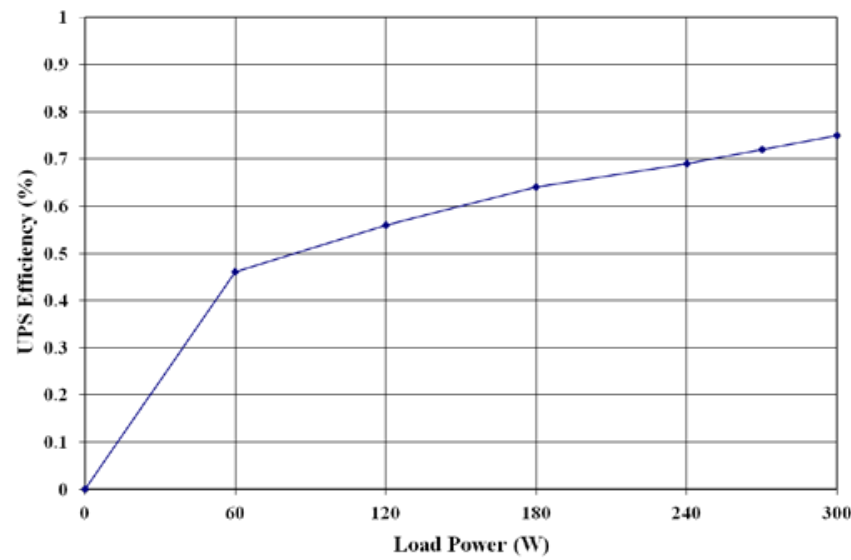

Fig. 8. UPS efficiency with load change measured in the UPS system using the CSC

The other is that the interruption of power source will take place in UPS system. In order to solve this problem, there are three types of methods as follows.

\subsubsection{Main and auxiliary PEMFC in parallel}

As shown in Fig. 1, when the intelligent control unit makes the K1 and K2 turn on, 
another auxiliary PEMFC is used to work with the main PEMFC in parallel, which indicates that two PEMFCs supply the power sources for the UPS system. When the short-circuit switches SC1 and SC2 are on, the main and auxiliary PEMFCs are in the short circuit of the current. Because they can supply the power source in parallel for UPS system if SC1 and SC2 are not turned on at the same time, it can avoid the power interruption of UPS, as shown in Fig. 9. Because two PEMFCs are connected in parallel, shorting the stacks does not always result in cell reversals in cells that happen to run out of hydrogen first during the shorting events.

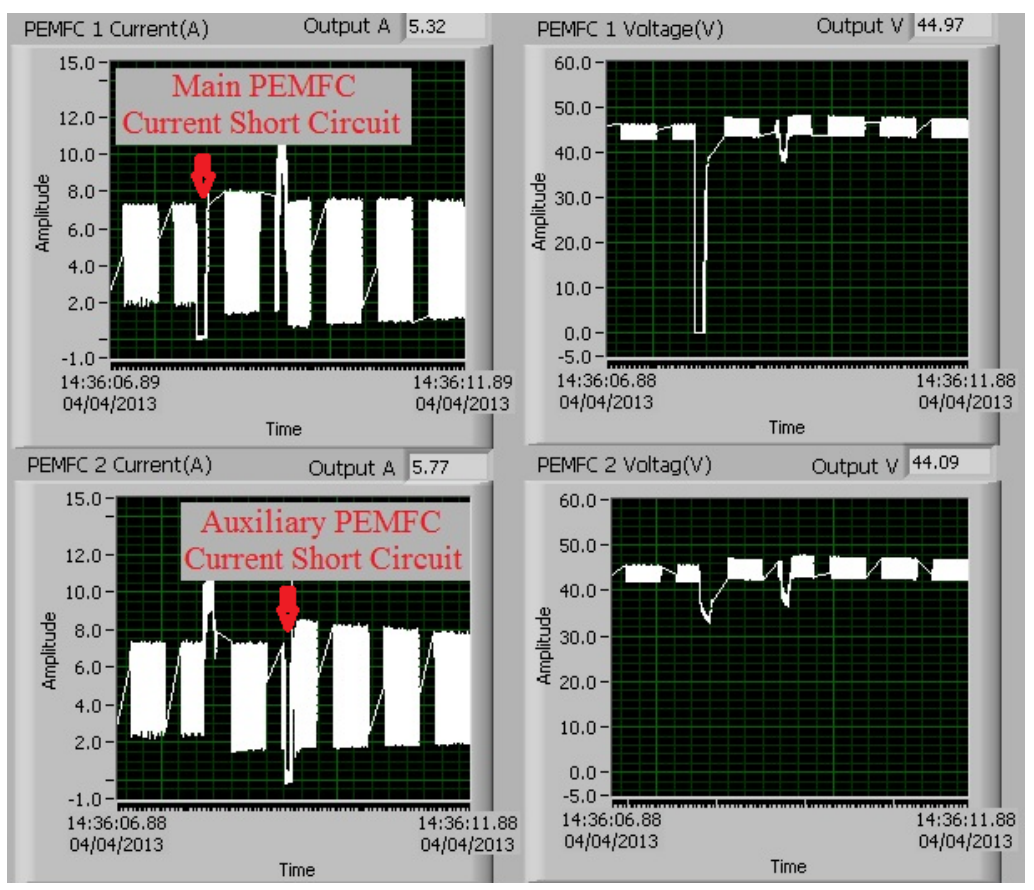

Fig. 9. Voltages and currents of main and auxiliary PEMFCs

Although the two PEMFCs are used to supply the power sources for UPS, their fuel supply and other devices are the same. For supplying the power sources for UPS, the size of two FCs can be reduced in half, and the total cost would not increase much.

However, limited by their inherent characteristics, the two PEMFCs have a long start-up time (usually several seconds to minutes) and slow response to instantaneous power demands. Compared with FCs, lead-acid or lithium rechargeable batteries have a rapid transient response without any warm up or start-up time, and their specific power 
capability is also much higher than that of FCs. Combination of FCs with small capacity of batteries or supercapacitors yields hybrid power sources that make the best use of the advantages of each individual device and may meet the requirements for the above mentioned applications regarding both high power and high energy densities. On the other hand, the UPS system employing a PEMFC as the main power source keeps adopting the battery or supercapacitor for protecting the PEMFC, in order to keep the water content balance, avoid excessive use and the reactants starvation of the PEMFC and feed power smoothly to the external load.

\subsubsection{Main PEMFC and batteries in parallel}

As shown in Fig. 1, when the intelligent control unit makes the K1 and K3 turn on, the 3-cell 12V/5Ah/10HR lead-acid batteries are used to work with the main PEMFC in parallel, which indicates that the main PEMFC will mainly supply the power sources for the UPS system, the batteries can supply auxiliary power source when the PEMFC starts up and is with a current short circuit to improve its performance. Their operating voltages and currents are shown in Figs. 10, 11 and 12, for the cases, when the main PEMFC starts up and fails, and the load charges sharply, respectively. The power source of UPS will be supplied with the batteries. 


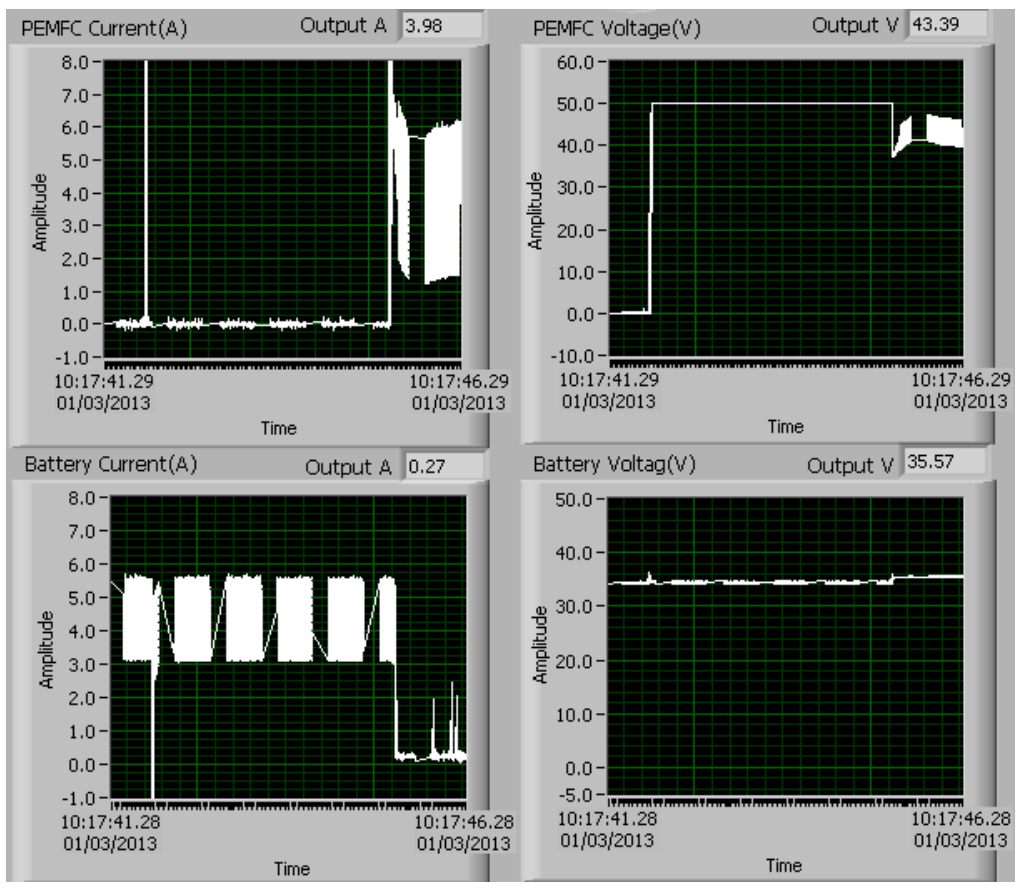

Fig. 10. Voltages and currents of main PEMFC and batteries when FC starts up
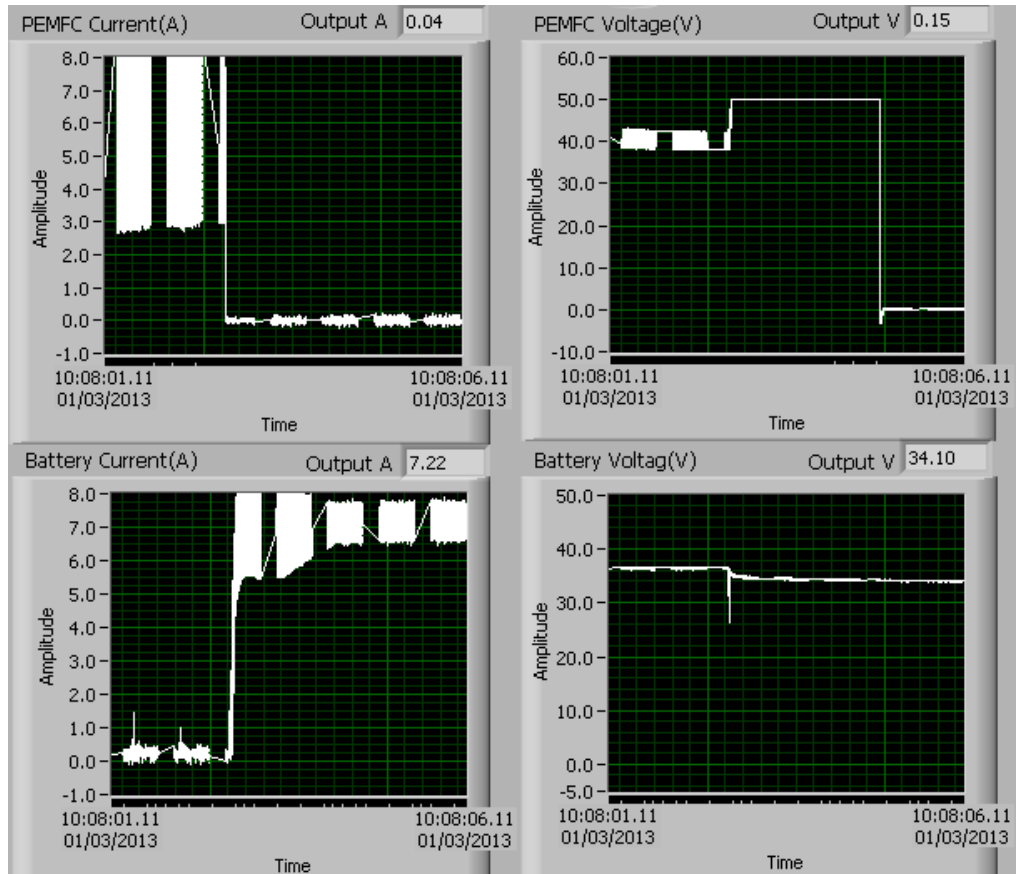

Fig. 11. Voltages and currents of main PEMFC and batteries when FC fails 


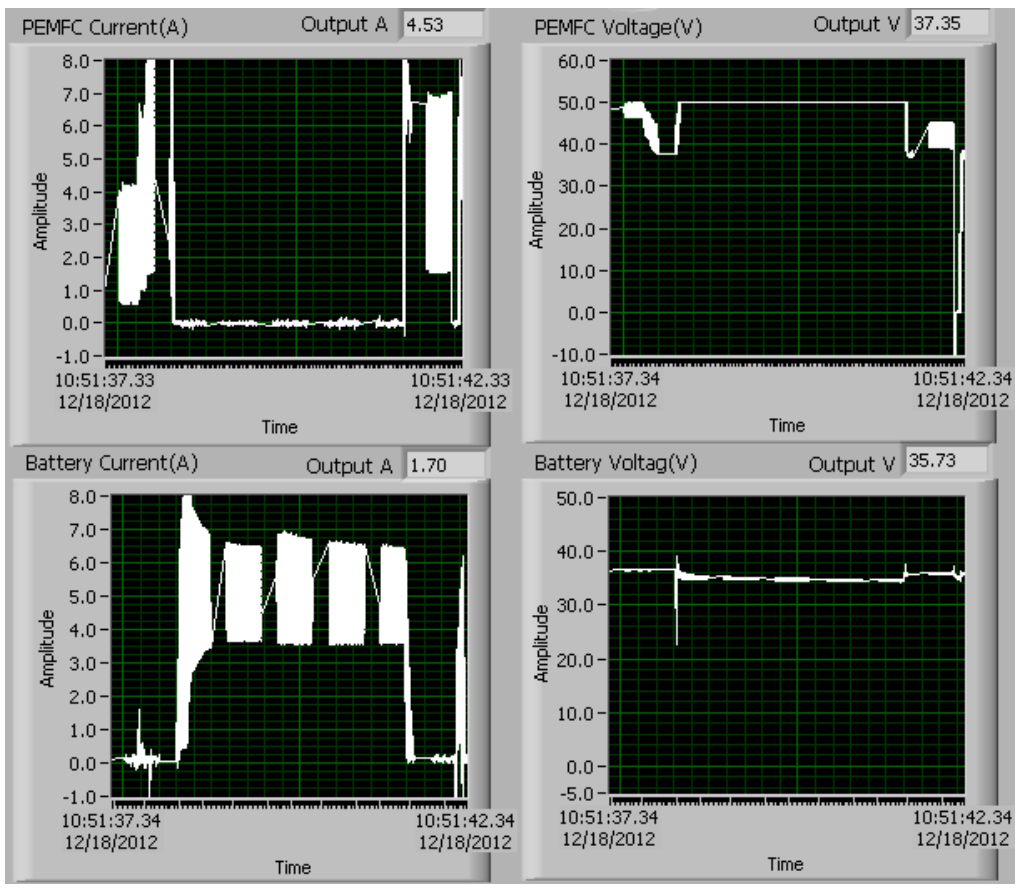

Fig. 12. Voltages and currents of main PEMFC and batteries when load charges sharply

\subsubsection{Main PEMFC and supercapacitors in parallel}

As shown in Fig. 1, when the intelligent control unit makes the K1 and K4 turn on, the 20-cell 120F/2.7V supercapacitors in series are used to work with the main PEMFC in parallel, which indicates that the main PEMFC will mainly supply the power sources for the UPS system, the supercapacitors can supply auxiliary power source when the PEMFC is under a current short circuit to improve its performance. Their operating voltages and currents of main PEMFC and supercapacitors are shown in Fig. 13. 


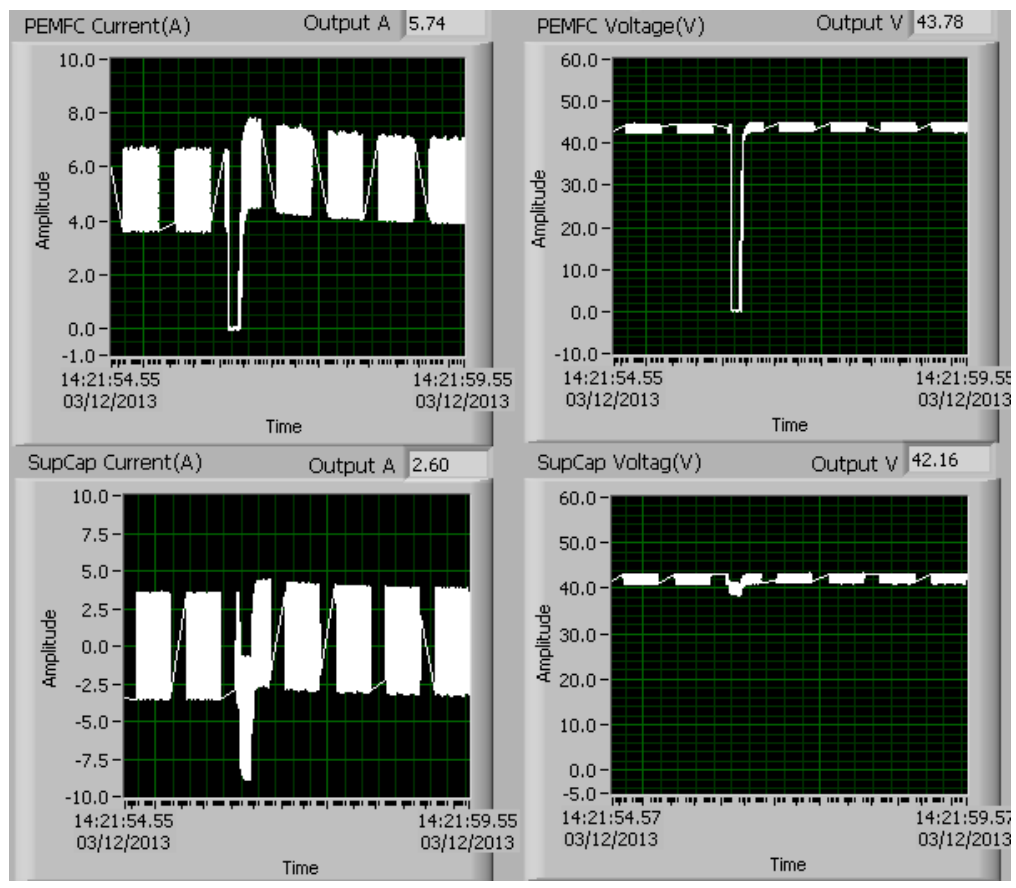

Fig. 13. Voltages and currents of main PEMFC and supercapacitors when FC is under a current short circuit

In conclusion, the three methods mentioned above can overcome the issues of power supplied for UPS system when using the CSC to improve the performance and extend the lifetime of PEMFCs.

\section{Conclusion}

This paper presents the considerations and architecture of lifetime extension and performance improvement for PEMFC in a UPS system with backup main and auxiliary PEMFCs, supercapacitor and battery power source. To prolong its lifetime and improve the performance of PEMFC when the stack starts up and during the operation processes, a current short circuit method and smart power and energy management strategy of two PEMFC generating power systems are employed and implemented. Based on the equivalent circuit model of a PEMFC and performance improvement mechanism of current short circuit, to meet the demand of performance for PEMFC when starting up, failing, and under a current short circuit, three kinds of experimental test and analysis are conducted and obtained experimentally, which are the operating performance of the main and auxiliary PEMFCs in parallel, the main PEMFC and lead-acid battery in 
parallel, and the main PEMFC and supercapacitor in parallel. The theoretical analysis and experimental results indicate that the developed current short circuit control strategy with backup hybrid PEMFC/battery/supercapacitor power sources is suitable for portable, backup, stationary power and vehicles applications.

\section{References}

[1] US FCs: Multi-year Research, Development and Demonstration Plan, 2011 Executive Summary, [online], available at http: //www.eere.energy.gov /hydrogenandfuelcells/mypp/pdfs/exec_sum.pdf

[2] Y.D. Zhan, Y.G. Guo, J.G. Zhu, and H. Wang. Intelligent uninterrupted power supply system with back-up FC/battery hybrid power source, J. Power Sources, 2008, 179(2):745-753.

[3] FC TEChNOLOGIES PROGRAM, FY 2013 Budget Request Rollout to Stakeholders of U. S. Department of Energy, [online], http://www.eere.energy.gov/hydrogenandfuelcells/pdfs/fy13_budget_request_roll out.pdf

[4] 2011 Technical Plan — FCs of U.S. Department of Energy, [online], http://www.eere.energy.gov/hydrogenandfuelcells/mypp/pdfs/fuel_cells.pdf

[5] DOE Hydrogen and FC Overview, ASME 2011- Plenary, 5th International Conference on Energy Sustainability, Washington, DC, August 8, 2011, http://www.eere.energy.gov/hydrogenandfuelcells/pdfs/asme_aug2011_plenary_o verview.pdf

[6] N. Bussayajarn, H. Ming, K.K. Hoong, W.Y. Stephen, and C.S. Hwa. Planar air breathing PEMFC with self-humidifying MEA and open cathode geometry design for portable applications, Int. J. Hydrogen Energy, 2009, 34(18):7761-7767.

[7] T. Ous, C. Arcoumanis. The formation of water droplets in an air-breathing PEMFC, Int. J. of Hydrogen Energy, 2009, 34(8):3476-3487. 
[8] H.H. Su, L.M. Xu, H.P. Zhu, Y.N. Wu, L.J. Yang, S.J. Liao, H.Y. Song, Z.X. Liang, V. Birss. Self-humidification of a PEMFC using a novel Pt/SiO2/C anode catalyst, Int. J. Hydrogen Energy, 2010, 35(15):7874-7880.

[9] H.G. Liang, L.P. Zheng, S.J. Liao. Self-humidifying membrane electrode assembly prepared by adding PVA as hygroscopic agent in anode catalyst layer, Int. J. Hydrogen Energy, 2012, 37(17):12860-12867.

[10] P.C. Pei, and H.C. Chen. Main factors affecting the lifetime of Proton Exchange Membrane fuel cells in vehicle applications: A review, Applied Energy, 2014, 125:60-75.

[11] Y.D. Zhan, J.G. Zhu, and H, Wang. Modeling and control of hybrid UPS system with backup PEMFC/battery, J. Electrical Power and Energy Systems, 2012, 43 (1):1322-1331.

[12] B. Guo, W.K. Na, B. Diong. FULL CELL Modeling, Control, and Applications, New York: CRC Press, 2009.

[13] A. J. Bard and L. R. Faulkner. ELECTROCHEMICAL METHODS Fundamentals and Applications (Second Edition), John Wiley \& Sons, Inc., New York, 2001.

[14] H.A. Gasteiger, S.S. Kocha, B. Sompalli, F.T. Wagner. Activity benchmarks and requirements for Pt, Pt-alloy, and non-Pt oxygen reduction catalysts for PEMFCs. Applied Catalysis B: Environmental, 2005, 56(1-2):9-35.

[15] J. Larminie, A. Dicks, FC Systems Explained, Second Edition, London: John Wiley \& Sons Ltd., 2003.

[16] X.Z. Yuan, H.J. Wang, PEMFC Electrocatalysts and Catalyst Layers: Fundamentals and Applications, Germany: Springer, 2008, 1-87. 
Figure Captions:

1. Block diagram of UPS system with backup PEMFC, battery and supercapacitor hybrid power sources

2. Equivalent circuit of a PEMFC

3. Schematic diagram of the PEMFC generating and test control system

4. Hybrid PEMFCs/battery/supercapacitor system test bench

5. Polarization curves of air-breathing stack with and without a current short circuit (CSC) control: temperature at $24-55^{\circ} \mathrm{C}$; pressure of hydrogen at $50-55 \mathrm{kPa}$; stoichiometry of hydrogen at 1.5

6. Long-term performances of air-breathing stack with and without a current short circuit (CSC) method: temperature at $55^{\circ} \mathrm{C}$; pressure of hydrogen at $50-55 \mathrm{kPa}$; stoichiometry of hydrogen at 1.5; current at 4.3A

7. PEMFC efficiency measured in the UPS system using CSC

8. UPS efficiency with load change measured in the UPS system using the CSC

9. Voltages and currents of main and auxiliary PEMFCs

10. Voltages and currents of main PEMFC and batteries when FC starts up

11. Voltages and currents of main PEMFC and batteries when FC fails

12. Voltages and currents of main PEMFC and batteries when load charges sharply

13. Voltages and currents of main PEMFC and supercapacitors when FC is under a current short circuit 




Fig. 1. Block diagram of UPS system with backup PEMFC, battery and supercapacitor hybrid power sources 


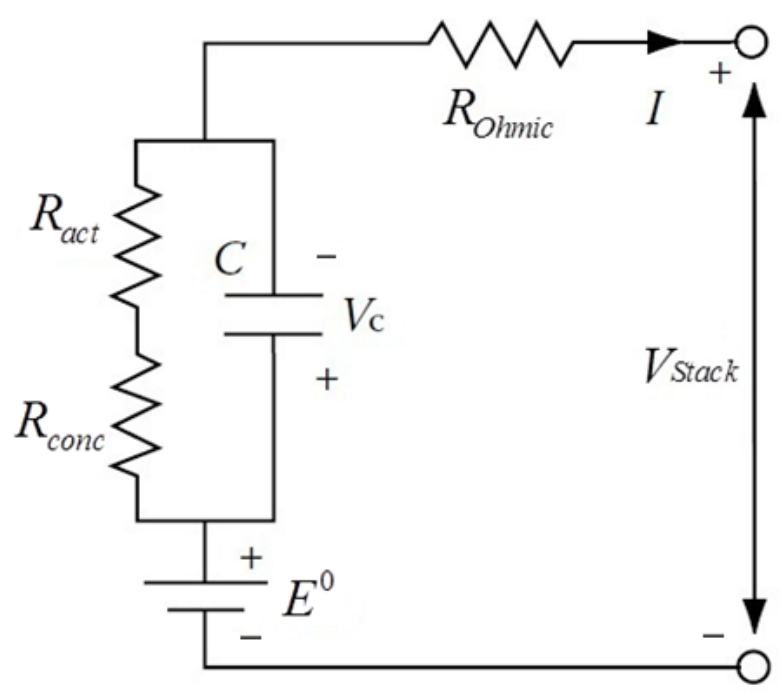

Fig. 2. Equivalent circuit of a PEMFC 


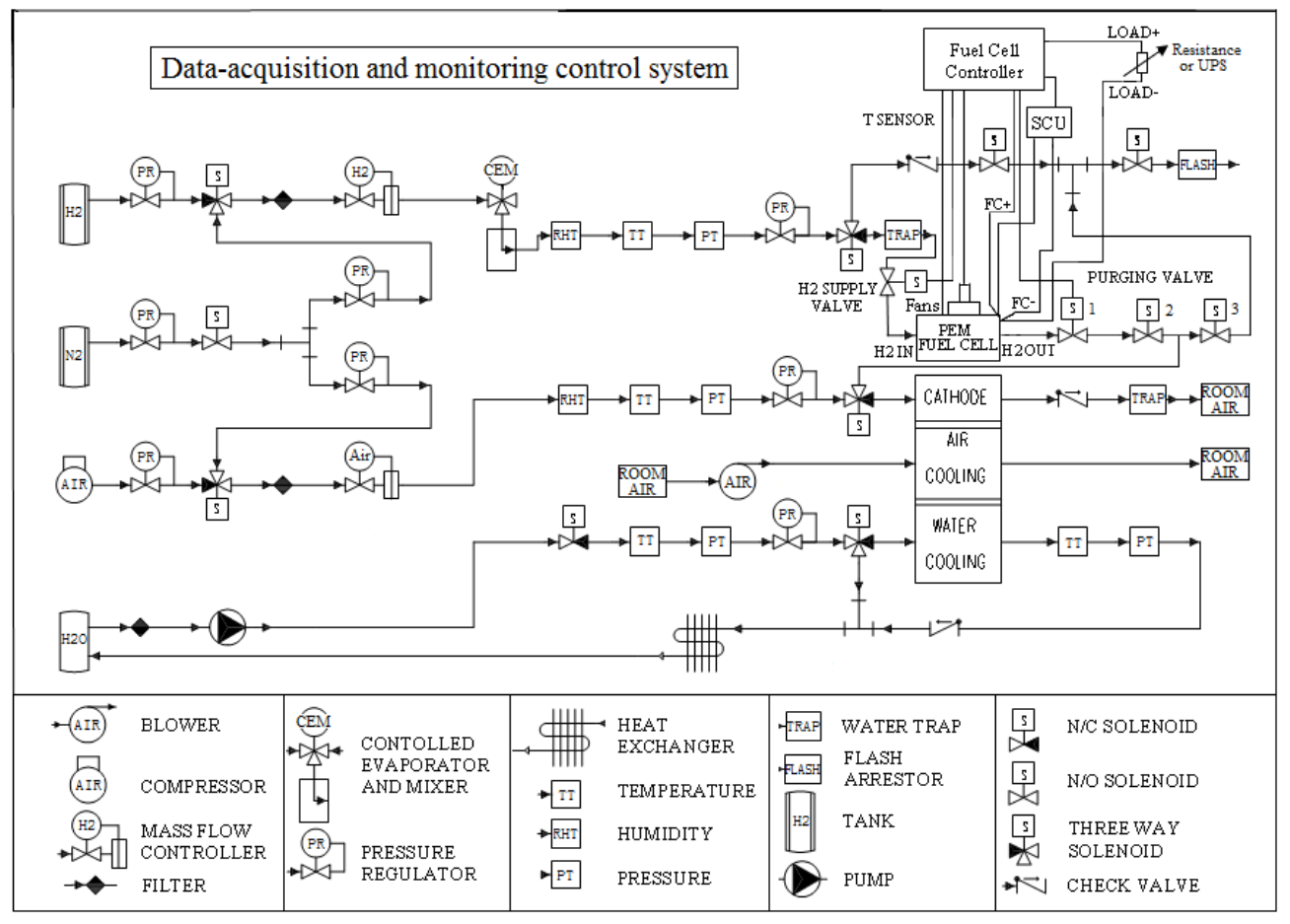

Fig. 3. Schematic diagram of the PEMFC generating and test control system 




Fig. 4. Hybrid PEMFCs/battery/supercapacitor system test bench 


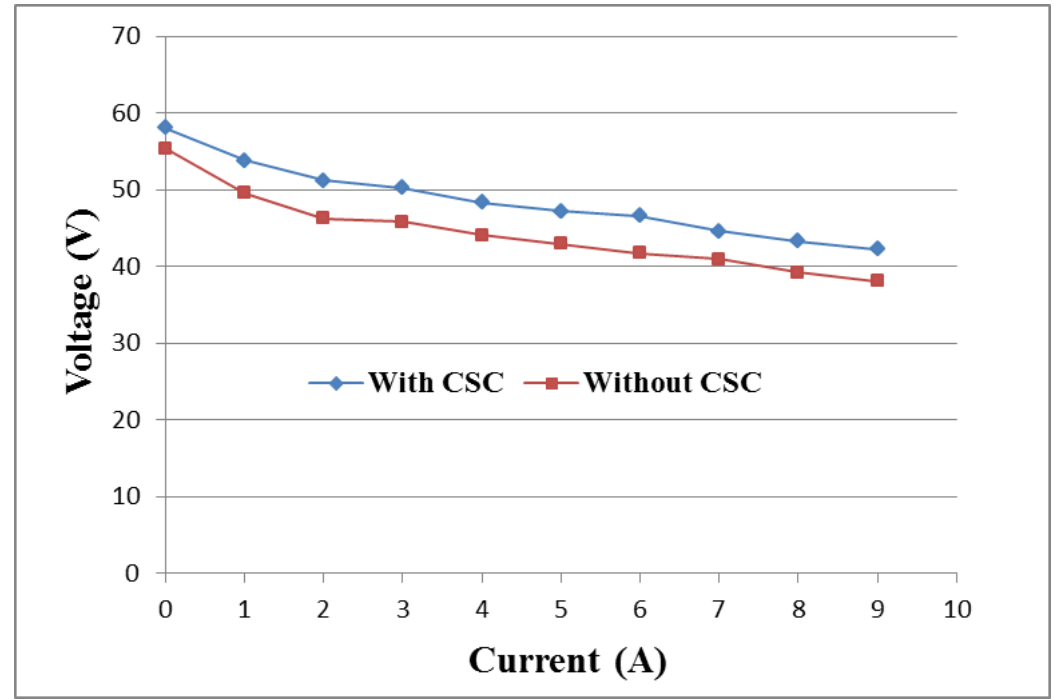

Fig. 5. Polarization curves of air-breathing stack with and without a current short circuit (CSC) control: temperature at $24-55^{\circ} \mathrm{C}$; pressure of hydrogen at $50-55 \mathrm{kPa}$; stoichiometry of hydrogen at 1.5 


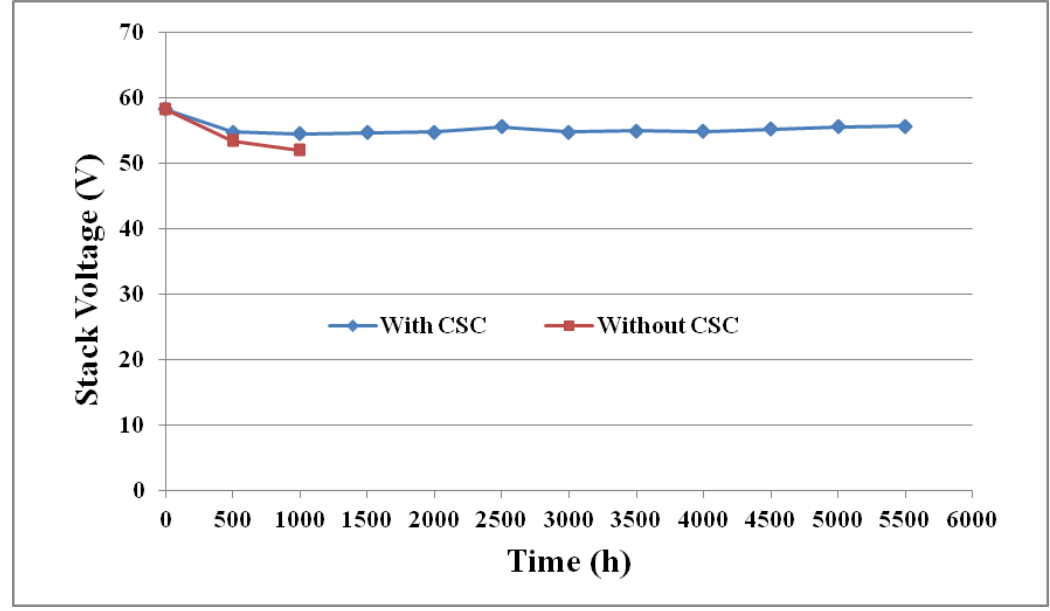

Fig. 6. Long-term performances of air-breathing stack with and without a current short circuit (CSC) method: temperature at $55^{\circ} \mathrm{C}$; pressure of hydrogen at $50-55 \mathrm{kPa}$; stoichiometry of hydrogen at 1.5 ; current at $4.3 \mathrm{~A}$ 


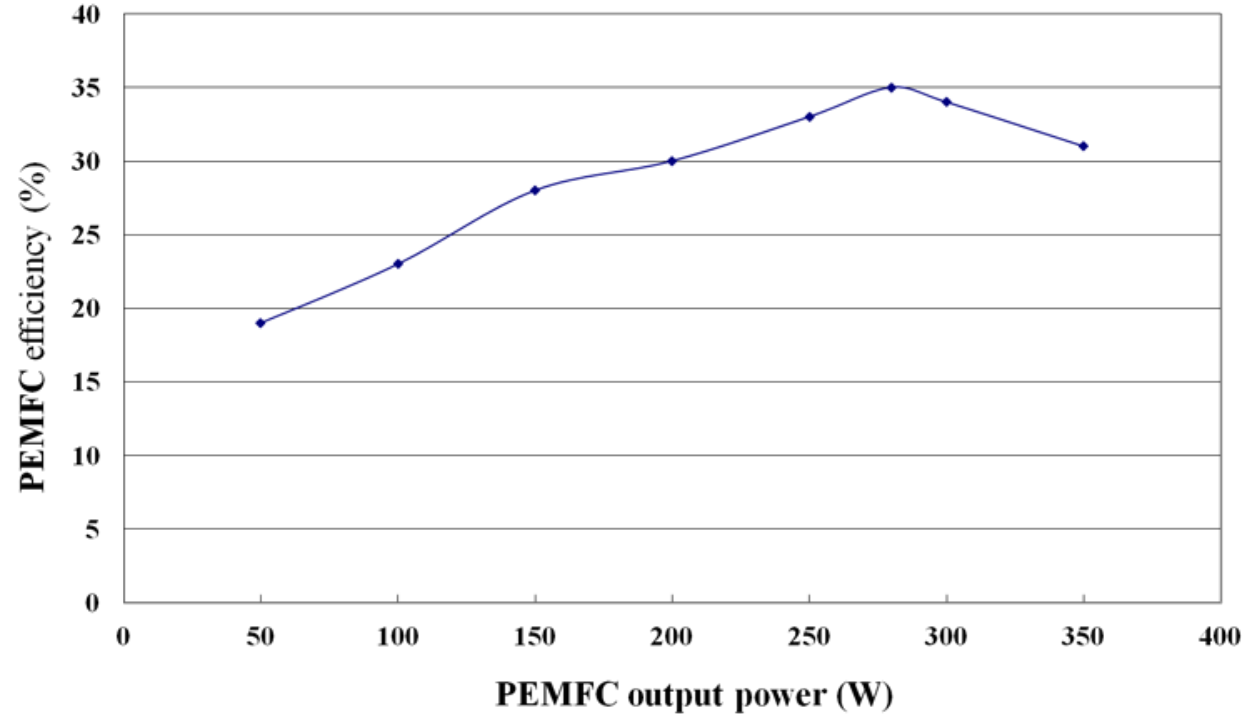

Fig. 7. PEMFC efficiency measured in the UPS system 


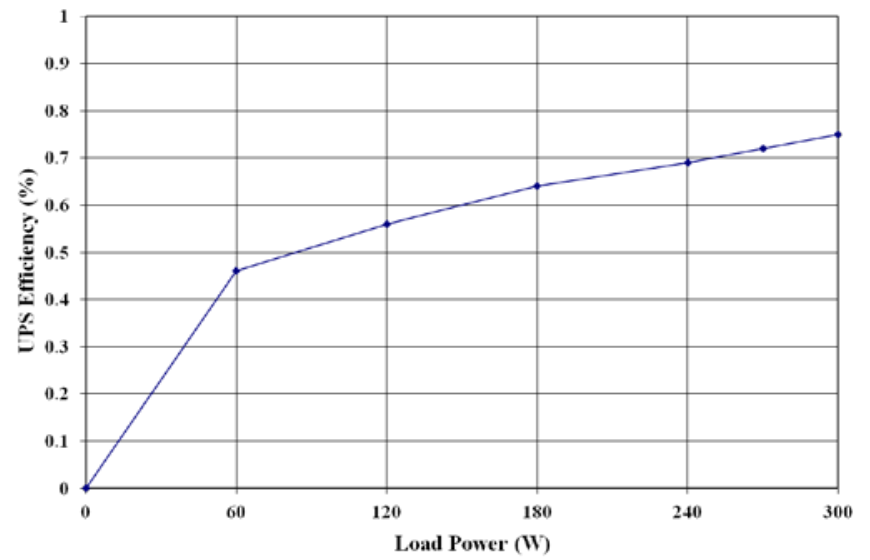

Fig. 8. UPS efficiency with load change measured in the UPS system using the CSC 


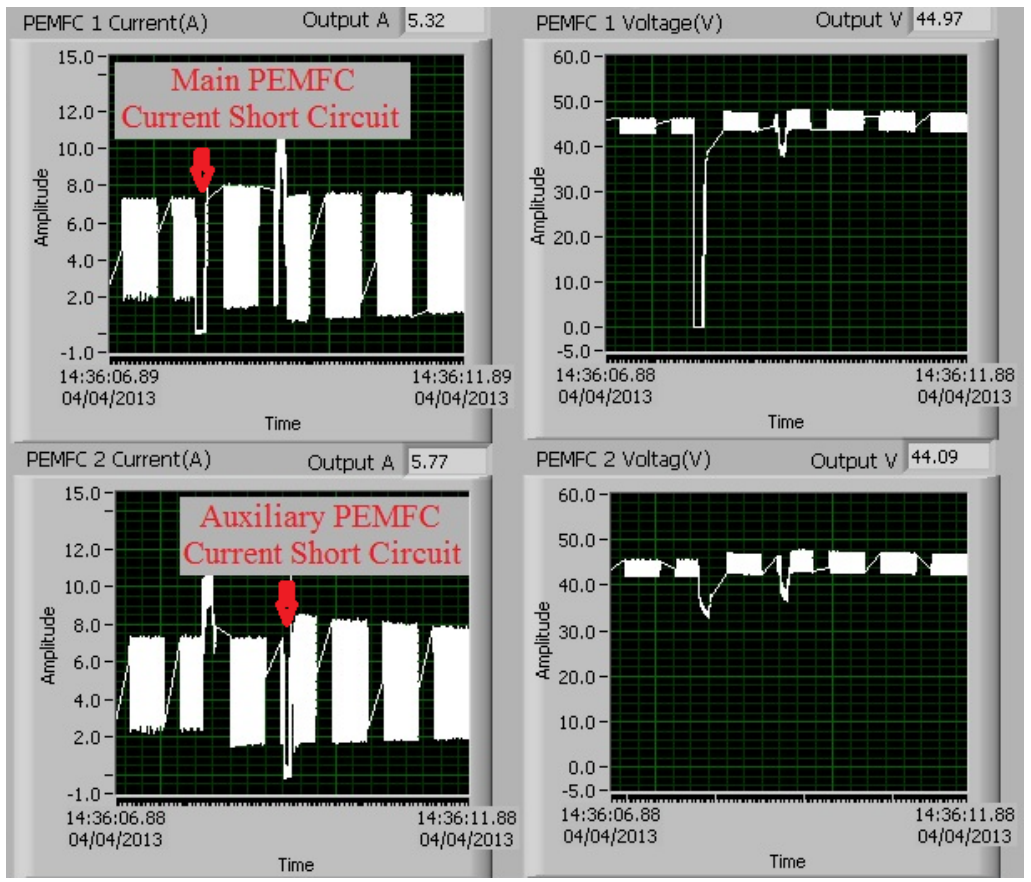

Fig. 9. Voltages and currents of main and auxiliary PEMFCs 


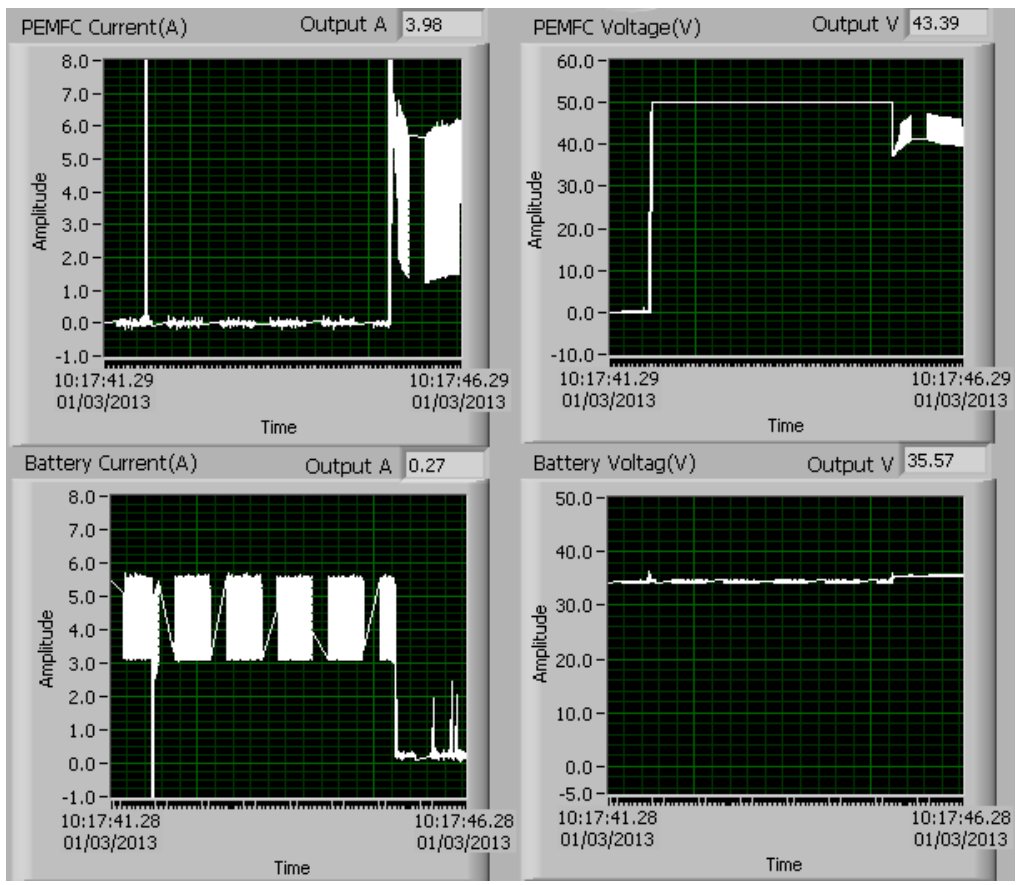

Fig. 10. Voltages and currents of main PEMFC and batteries when FC starts up 


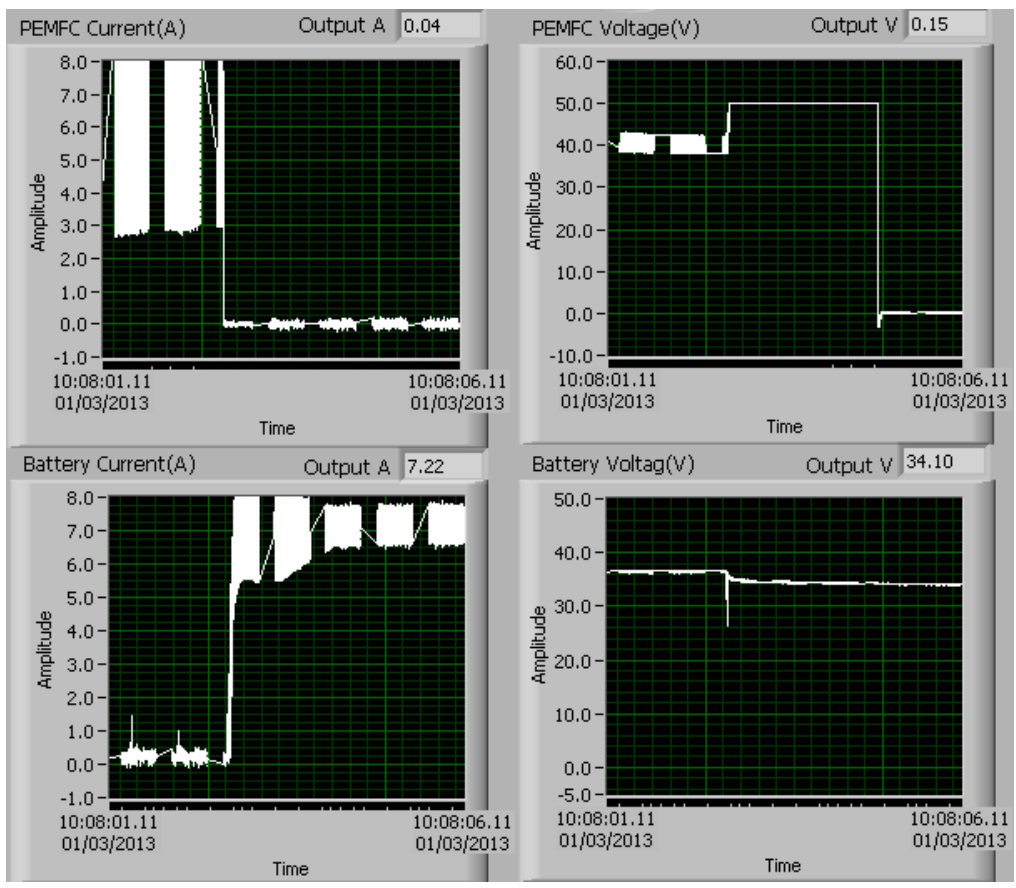

Fig. 11. Voltages and currents of main PEMFC and batteries when FC fails 


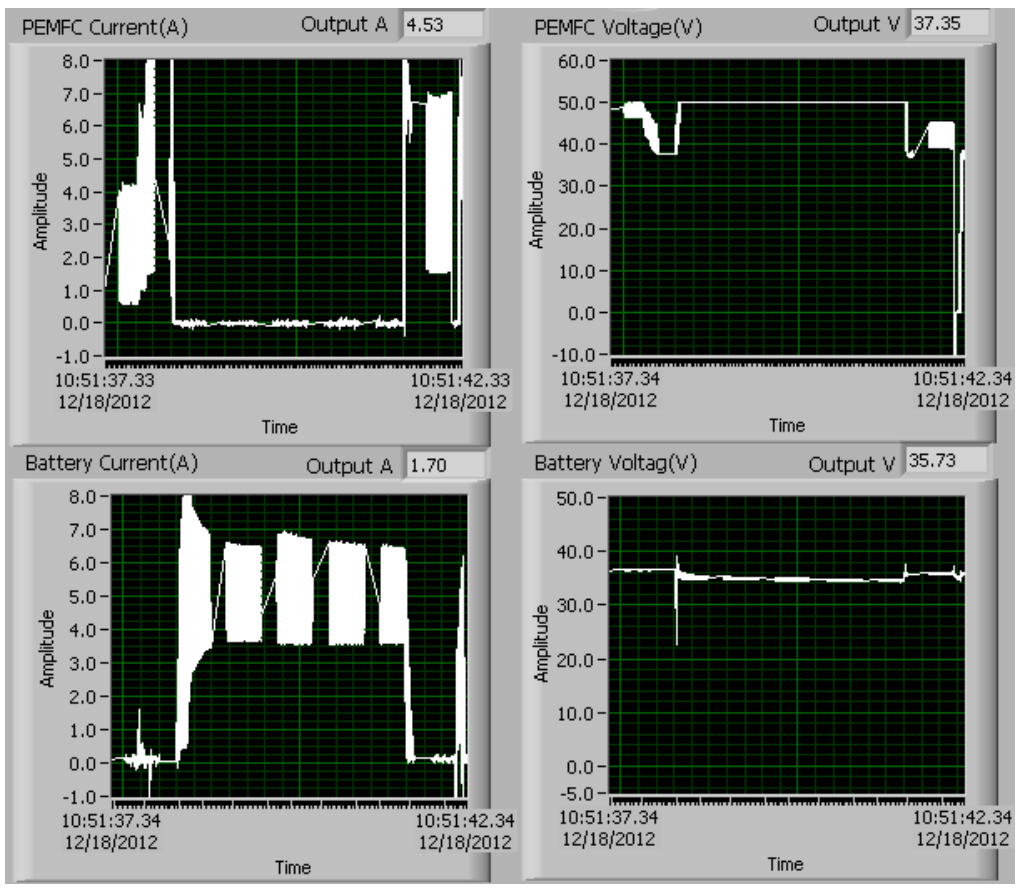

Fig. 12. Voltages and currents of main PEMFC and batteries when load charges sharply 


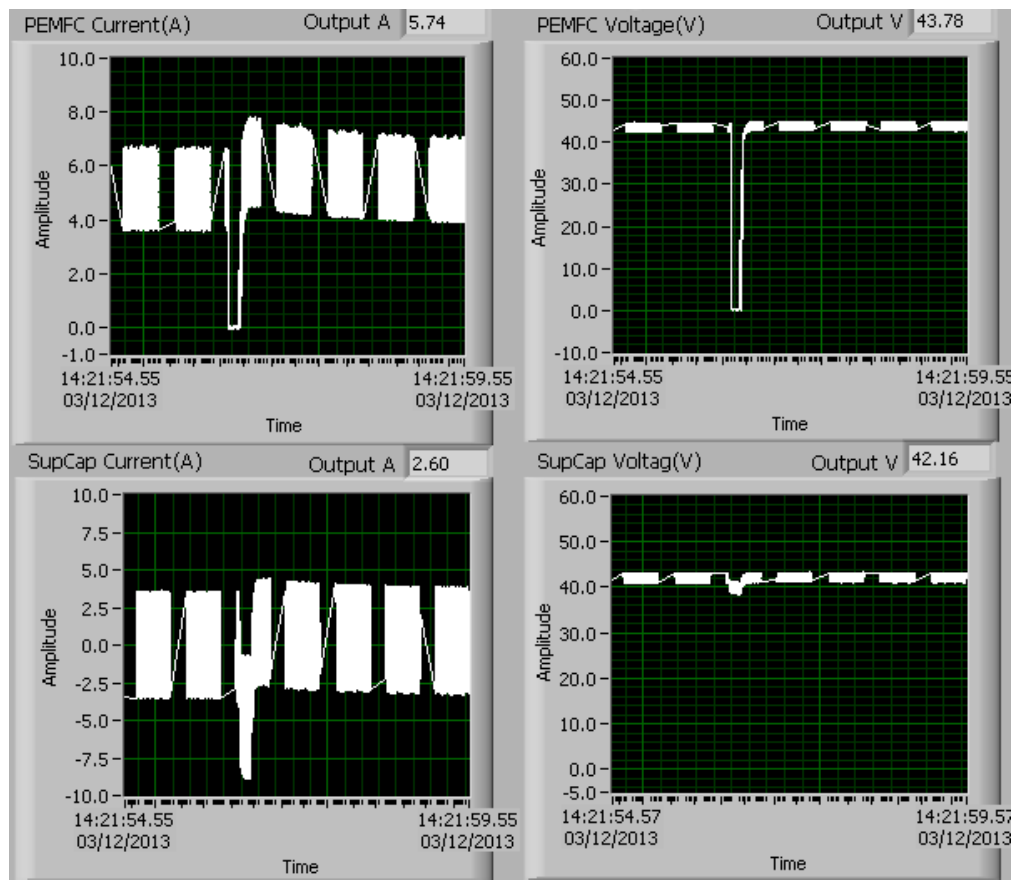

Fig. 13. Voltages and currents of main PEMFC and supercapacitors when FC is under a current short circuit 